\title{
The Effect of Hybridoma Antibody Administration upon Neutrophil Kinetics during Experimental Type III Group B Streptococcal Sepsis
}

\author{
ROBERT D. CHRISTENSEN, ${ }^{(36)}$ GERALD ROTHSTEIN, HARRY R. HILL, AND SETH H. PINCUS \\ Departments of Pediatrics, Internal Medicine and Pathology, University of Utah School of Medicine and Primary
} Children's Medical Center, Salt Lake City, Utah, USA

\begin{abstract}
Summary
Groups of newborn rats were transthoracically inoculated with 1 $\times 10^{6}$ type III group B streptococci/g body wt, either alone or in combination with 1.5 microgram/g body wt of type-specific antibody derived fom hybridoma cell lines. Ninety-four percent of the animals who received bacteria alone died. In contrast, none of those treated with antibody died $(P<0.005)$. Kinetic studies suggested that antibody may have offered protection, in part, by facilitating the neutrophil response. Animals who received only bacteria exhibited a marked neutropenia $\left(20 \pm 18 / \mathrm{mm}^{3}\right.$, mean \pm S.E.M.) whereas infected animals treated with antibody did not $\left(3800 \pm 30 / \mathrm{mm}^{3}, P<0.001\right)$. Furthermore, within $2 \mathrm{~h}$ of inoculation, antibody-treated animals mobilized stored neutrophils, whereas significant neutrophil mobilization did not occur in the animals which received bacteria alone until $6 \mathrm{~h}$. In the animals receiving bacteria alone, exhaustion of the neutrophil supply quickly occurred (remaining storage neutrophils at $6 \mathrm{~h}, 0.2 \pm 0.1$ $\times 10^{6}$ cells). In contrast, animals, which received antibody, maintained an adequate supply of stored neutrophils $\left(7.0 \pm 0.4 \times 10^{6}\right.$ $P<0.001$ ). The migration of neutrophils to the site of inoculation was measured by assaying the lungs' content of myeloperoxidase, a marker enzyme for granulocytes. The right and left lungs of animals not receiving antibody accumulated the same quantity of neutrophils, with peak pulmonary neutrophil accumulation occurring $6 \mathrm{~h}$ after the infection. In antibody recipients, however, the inoculated lung accumulated significantly more neutrophils than the opposite lung and peak pulmonary neutrophil accumulation occurred at 2 rather than $6 \mathrm{~h}$.
\end{abstract}

\section{Abbreviations}

$A B$, antibody

GBS, group B streptococci

$\mathrm{i} / \mathrm{t}$, immature/total

MPO, myeloperoxidase

PBS, phosphate buffered saline

PMN, polymorphonuclear neutrophils

When newborn rats are inoculated with $10^{6} \mathrm{GBS} / \mathrm{g}$ body wt, a mortality rate of $90-100 \%$ characteristically occurs $(1,5,27)$. Before death, the animals invariably develop profound neutropenia, a maximal "left shift," as quantified by the immature/total neutrophil ratio, and exhaustion of their mature marrow neutrophil reserves (6). The administration of IgM anti-type III GBS antibody derived from hybridoma cell lines has been demonstrated to dramatically reduce mortality in this model (29). But the mechanism whereby this antibody provides protection from death has not been completely elucidated. We hypothesized that in addition to acting as a potent opsonin, the antibody might in some way facilitate release of stored neutrophils, or improve neutrophil migration to the site of infection. We also wondered whether animals protected from death by antibody administration would develop the profound neutropenia and neutrophil storage pool depletion characteric of neonatal animals with GBS that die $(6,7,13)$. In order to test these hypotheses, we measured the circulating and storage neutrophil pools after intrapulmonary inoculation of either GBS alone or GBS plus antibody. In addition, we estimated the migration of neutrophils to the site of inoculation by measuring the lungs' content of myeloperoxidase, a marker enzyme for neutrophils $(3,4)$.

In the present experiments, the administration of antibody had significant and previously undescribed effects upon the release of neutrophils from storage sites and also on the accumulation of neutrophils in tissues. In addition, we observed that animals protected from death by antibody administration did not develop either neutropenia or exhaustion of the mature marrow neutrophil reserves.

\section{MATERIALS AND METHODS}

Animal inoculation. Sprague Dawley albino rats (Simonson Laboratories, Gilroy, CA) were used for experimentation during the first $24 \mathrm{~h}$ of life. The rat pups were separated from the mothers and after washing the right lateral chest wall with povidone-iodine (Perdue Frederich Co., Norwalk, CT) followed by 70\% ethyl alcohol, the right lung was transthoracically injected with $6 \mathrm{mi}$ croliters of bacterial suspension containing $1 \times 10^{9}$ organism $/ \mathrm{ml}$, plus 1 microliter ( 9.0 micrograms protein) of either hybridomaderived IgM anti-type III GBS antibody, IgM hybridoma antibody directed against TGAL, a non-streptococcal antigen or 1 microliter of PBS. The bacterial inoculum equaled $10^{6}$ organism/g body wt and the antibody inoculum was 1.5 micrograms of protein $/ \mathrm{g}$ body wt. Injection was accomplished with a microliter glass syringe (Hamilton Co., Whittier, CA). After the injections, animals were returned to mothers until they were sacrificed 2,6 , or $20 \mathrm{~h}$ later.

The type III GBS strain was isolated from an infected human infant, identified by the precipitin method using rabbit antisera (17), and grown overnight at $37^{\circ} \mathrm{C}$ in Todd-Hewitt broth. After washing with $\mathrm{PBS}$, aliquots were frozen at $-70^{\circ} \mathrm{C}$. Before inoculation into animals, the aliquots were thawed and grown to logarithmic phase in fresh Todd-Hewitt broth. Bacteria were then sedimented by centrifugation and the concentrated organisms were washed three times in PBS. The suspensions were then diluted in PBS to an optical density of 0.9 at $620 \mathrm{~nm}$ (Spectronic 20 Bausch and Lomb, Inc., Rochester, NY) producing a final concentration of $1 \times 10^{9}$ colony forming unit $/ \mathrm{ml}$.

In order to determine whether the animals inoculated with GBS and GBS + AB actually became infected, blood and pleural surface cultures were obtained $4 \mathrm{~h}$ after the inoculation. In addition, both the GBS and the GBS + AB used for in vivo inoculation were inoculated in vitro into fresh Todd-Hewitt broth.

Hybridoma antibody preparation. The details of production and characterization of monoclonal antibodies have been described 
elsewhere (25). In brief, mice were multiply immunized with live type III GBS (control antibody was made by multiple injections with the synthetic polypeptide TGAL). Animals were sacrificed and their spleens removed. Spleen cells were then fused with nonsecreting SP 2/0 cells using polyethylene glycol. After incubation in selective media containing hypoxanthine, aminopterin, and thymidine, antibody secreting cells were detected using an enzyme-linked immunoassay (26). Cells were cloned by limiting dilution. Nine cloned cell lines were produced. Three reacted with all GBS and six reacted only with type III GBS; all were IgM. Ascites was collected from animals injected intraperitoneally with hybridoma cells. Antibody preparations for these experiments were made by dialyzing ascites fluid against distilled water and resuspending the precipitate in PBS.

Quantification of circulating and storage neutrophils. Two, six, and twenty hours after inoculation, animals were sacrificed. Blood neutrophil concentration was measured by cutting the external juglar vein with scissors, and obtaining 10 microliters of blood via a micropipet (Drummond Scientific Co., Broomall, PA), which was then diluted in cetramide (ethylhexodecyldimethylammonium bromide, Eastman Kodak Co., Rochester, NY) for electronic cell counting (Coulter Electronics, Hialeah, FL). Blood smears were stained with Wright stain and differential counts performed.

The total neutrophil storage pool and neutrophil proliferative pool were quantified from individual animals using the methods we have previously discribed $(5,6)$; flushing the marrow from both femurs into Hank's balanced salt solution and passing the liver and spleen through sieves for nucleated cell count and differential counting.

Quantification of lung myeloperoxidase content. Right and left lungs were removed and placed into separate glass beakers which contained $2.0 \mathrm{ml}$ hexadecyltrimethylammonium bromide (HTAB, Sigma Chemical Co., St Louis, MO) and were then minced with scissors. The specimens were homogenized in a tissue homogenizer (Ultra Turrax, West Germany), freeze-thawed three times, sonified (Heat Systems Untrasonics Inc., Plainview, NY) and then centifuged at $40,000 \times g$ for $15 \mathrm{~min}$. The extracted myeloperoxidase was then assayed spectrophotometrically. One-tenth $\mathrm{ml}$ of material to be measured was mixed with $2.9 \mathrm{ml}$ of $50 \mathrm{mM}$ phosphate buffer, pH 6.0 , containing $0.167 \mathrm{mg} / \mathrm{ml} o$-dianisidine dihydrochloride (Sigma Chemical Co) and 0.0005\% hydrogen peroxide (Mallinckrodt, Paris, KY). These conditions were em- ployed because, as we have previously demonstrated, they confer increased sensitivity to the assay $(3,4)$. The change in absorbance at $460 \mathrm{~nm}$ was measured with a Beckman CU spectrophotometer (Beckman Instruments, Fullerton, CA) with a recording attachment (Gilford Instruments Laboratories., Oberlin, $\mathrm{OH}$ ).

Data were analyzed by means of Student's $t$ test and the Fisher Exact test.

\section{RESULTS}

The mortality observed when newborn rats were transthoracically inoculated with $1 \times 10^{6}$ group B streptococci/g body wt is shown in Figure 1. Sixty-two of 66 animals inoculated with GBS alone died within $24 \mathrm{~h}$ of the inoculation. Similarly, 38 of 40 animals inoculated with GBS plus a control hybridoma IgM antibody (directed against TGAL) died. In contrast, no deaths were observed among 65 rats inoculated with GBS plus hybridoma-derived IgM anti-type III GBS antibody (GBS $+\mathrm{AB})$ in a dose of 1.5 microgram/g body wt $(P<0.005)$. Four hours after inoculation all animals tested grew type III GBS in blood and pleural surface cultures. When both GBS and GBS + AB were inoculated directly into Todd-Hewitt broth, growth of organisms invariably occurred. The changes in blood neutrophil count after inoculation with either GBS alone or GBS + AB are illustrated in Figure 2. Two hours after inoculation the blood neutrophil concentrations were similar in the two groups, but after $6 \mathrm{~h}$, animals receiving GBS alone were profoundly neutropenic $(400 \pm 20$ neutrophil $/ \mathrm{mm}^{3}$ ) compared to GBS + AB animals (2200 \pm 50 / $\mathrm{mm}^{3}, P<0.005$ ). After $20 \mathrm{~h}$ this difference was even more pronounced: the group that received GBS alone had essentially no circulating neutrophils $\left(40 \pm 20 / \mathrm{mm}^{3}\right)$ whereas GBS + AB animals maintained a blood neutrophil count within the normal range $\left(3800 \pm 30 / \mathrm{mm}^{3}, P<0.001\right)$.

The lower panel of Figure 2 depicts the "left shift" in these two groups. Virtually all inoculated animals had an elevated $i / t$ neutrophil ratio when compared with noninfected controls, but $20 \mathrm{~h}$ after inoculation the animals who received GBS alone had an $i / t$ neutrophil ratio of $0.98 \pm 0.04$, and many of the animals had no mature PMN observed during their blood leukocyte differential counts. This differed sharply from the $i / t$ ratio of $0.55 \pm 0.02$ at $20 \mathrm{~h}$ in the animals inoculated with GBS $+\mathrm{AB}(P<0.001)$.

The size of the neutrophil storage pool (all PMN + band

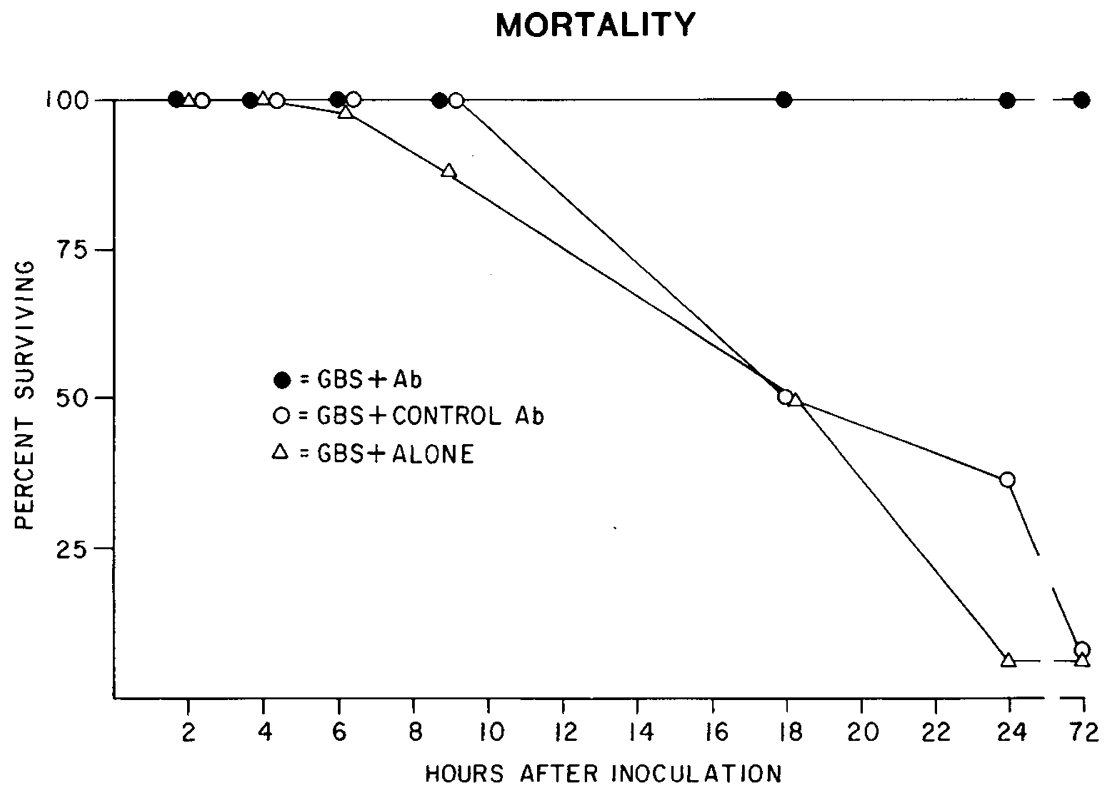

Fig. 1. Mortality observed amoung three groups of newborn rats. All groups were transthoracically inoculated with $1 \times 10^{6}$ type III group B streptococci/g body wt. In addition, Group 1 (closed circles), received 1.5 micrograms/g body wt of hybridoma-derived IgM type specific antibody, Group 2 (open circles) received 1.5 micrograms/g body wt of a control hybridoma-derived IgM antibody, and Group 3, (triangles) received an equal volume of phosphate buffered saline. 


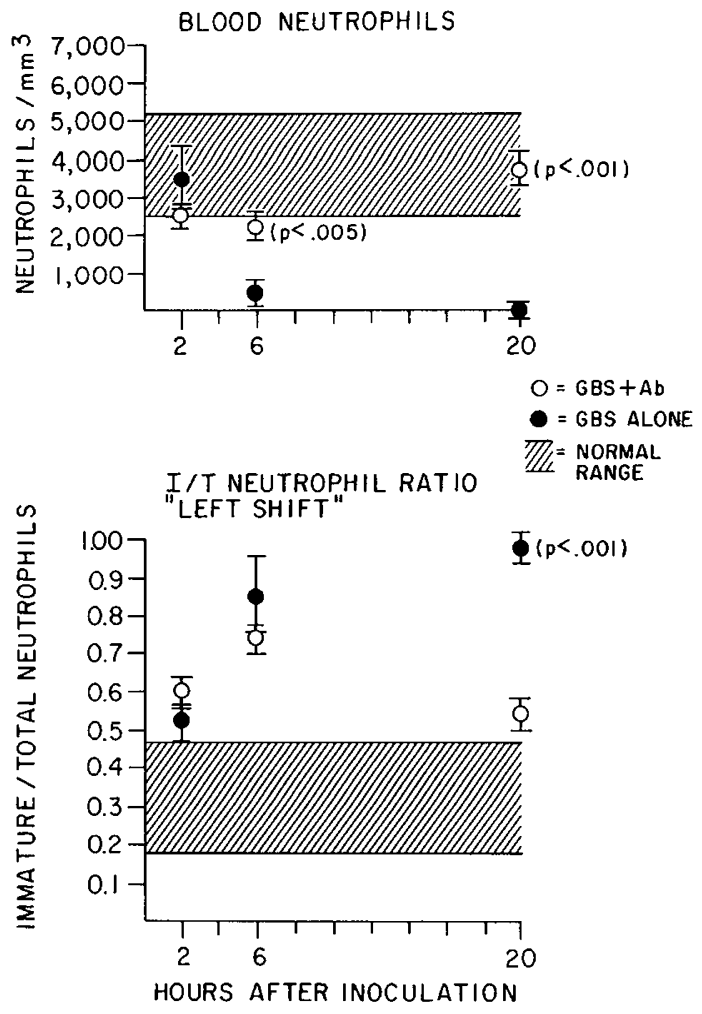

Fig. 2. Upper panel. Blood neutrophils in newborn rats after inoculation with either group B streptococci alone (solid circles) or group B streptococci plus type-specific hybridoma-derived IgM antibody (open circles). The circle indicates the mean of 6-10 animals and the bracket, the standard error of the mean. Lower panel. The "left shift," quantified by the immature/total blood neutrophil ratio, in newborn rats after inoculation with either group B streptococci alone (solid circles) or group B streptococci plus type-specific hybridoma-derived IgM antibody (open circle). The circle indicates the mean of 6-10 animals and the bracket, the standard error of the mean.

neutrophils + metamyelocytes within the bone marrow + liver + spleen) and the neutrophil proliferative pool (all myelocytes + promyelocytes + myleoblasts) in the GBS alone and GBS + AB groups are illustrated in Figure 3. After $2 \mathrm{~h}$, the GBS $+\mathrm{AB}$ animals had released about $50 \%$ of their neutrophil reserves. In contrast, animals receiving GBS alone had not released significant numbers of neutrophils after $2 \mathrm{~h}$. Six hours after inoculation, the group of animals that received GBS alone, had released almost all of their stored neutrophils whereas the neutrophil reserves of GBS $+\mathrm{AB}$ animals were not exhausted $(P<0.005)$. Twenty hours after the inoculation, the neutrophil reserves of animals inoculated with GBS alone were exhausted $\left(0.1 \pm 0.1 \times 10^{6}\right.$ cells $)$ in contrast to the GBS + AB group whose neutrophil reserves were only moderately diminished $\left(7.0 \pm 0.4 \times 10^{6}\right.$ cells, $\left.P<0.001\right)$. The proliferative neutrophil pool of GBS alone animals did not differ from that of the GBS + AB group at 2,6, or $20 \mathrm{~h}$, although both groups exibited values somewhat below normal after $6 \mathrm{~h}$, and both increased into the normal range by $20 \mathrm{~h}$.

The accumulation of neutrophils in the lungs was determined by extracting and assaying the lungs' content of MPO, 2, 6, and $20 \mathrm{~h}$ after the inoculation. The data are shown in Figure 4. It can be seen that in both groups the lungs' content of myeloperoxidase increased as neutrophils accumulated in response to the infection. The group that received GBS alone accumulated neutrophils in both the right (inoculated) and left (noninoculated) lungs, and the degree of neutrophil accumulation in the two lungs did not differ at 2 or $6 \mathrm{~h}$. In contrast, animals receiving GBS + AB accumulated more neutrophils in the injected lung $2 \mathrm{~h}$ after the inoculation. This early accumulation of pulmonary neutrophils in GBS + AB animals coincided with earlier mobilization of neutrophils from the storage sites as shown in Figure 3.

\section{DISCUSSION}

The unusual susceptibility of newborn infants to mortality from bacterial sepsis has been clearly demonstrated in both clinical and laboratory studies (22). The explanation for this phenomenon appears to be complex, involving both an incomplete development of the neutrophil system $(8,14,16,23,24)$ and lack of type-specific antibodies to major bacterial pathogens $(2,15,21)$. It is well recognized that because of these deficiencies, many neonates who contract bacterial sepsis cannot be saved with standard antibiotic therapy alone; therefore, much attention has been paid to additional, adjunctive measures, such as exchange transfusion $(31,32)$, neutrophil transfusion $(9,10,19,20,33)$ and plasma/antibody administration $(28,30)$ in order to improve the outcome of these patients.

An additional measure with possible investigative as well as therapeutic ramifications was recently presented by Shigeoka and coworkers (29). They demonstrated that administration of typespecific IgM antibody prevented mortality due to intraperitoneal GBS inoculation in neonatal rats. In the present study we wished to explore the salutory effect of this antibody and postulated that in addition to being opsonic it might also facilitate the neutrophil response because defective neutrophil supply and migration have already been demonstrated to be mechanistically important in this animal model $(6,8,11)$. We were particularly interested in determining if animals saved from death by antibody administration survived despite becoming profoundly neutropenic and neutrophil depleted or whether the antibody, in some way, protected the

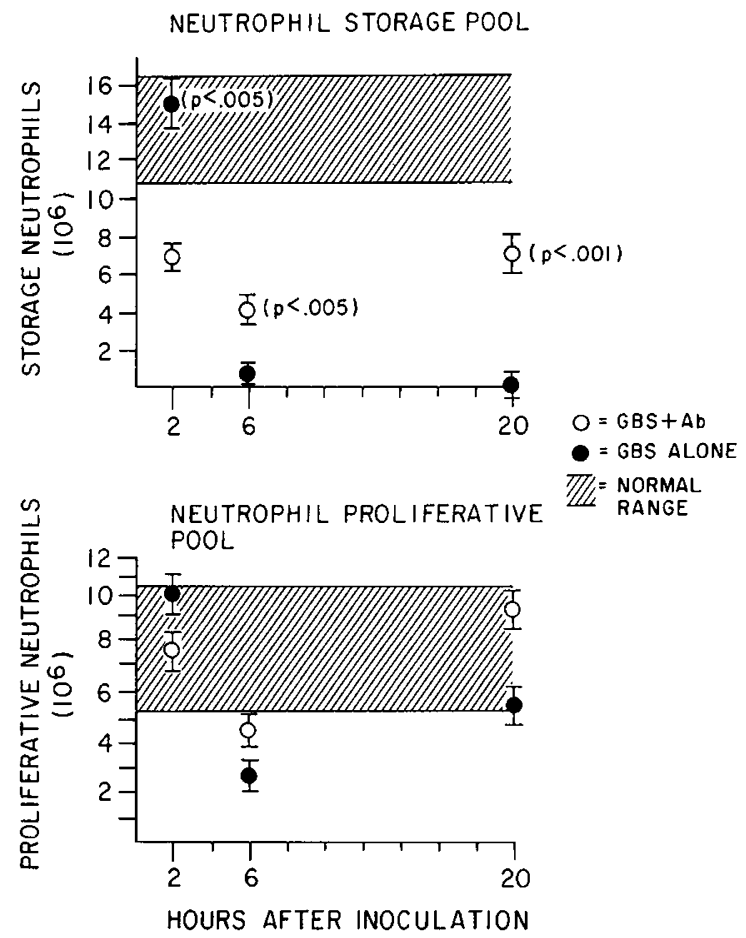

Fig. 3. Upper panel. The neutrophil storage pool (all PMNs + band neutrophils + metamyleocytes within the liver, spleen and marrow) in newborn rats after inoculation with either group B streptococci alone (solid circles) or plus type-specific hybridoma-derived IgM antibody (open circles). The circle represents the mean of 6-10 animals, the bracket the standard error of the mean. Lower panel. The neutrophil proliferative pool (all myelocytes + promyelocytes + myeloblasts within the liver, spleen and marrow) in newborn rats after inoculation with either group $B$ streptococci alone (solid circles) or plus type-specific hybridoma-derived IgM antibody (open circles). The circle represents the mean of 6-10 animals, the bracket, the standard error of the mean. 


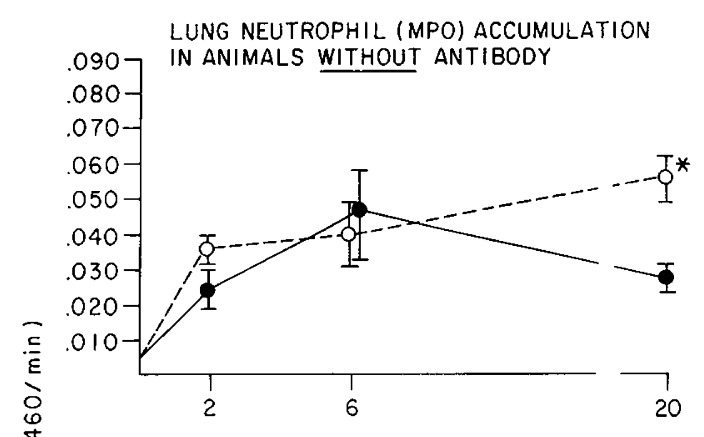

LUNG NEUTROPHIL (MPO) ACCUMULATION IN ANIMALS WITH ANTIBODY

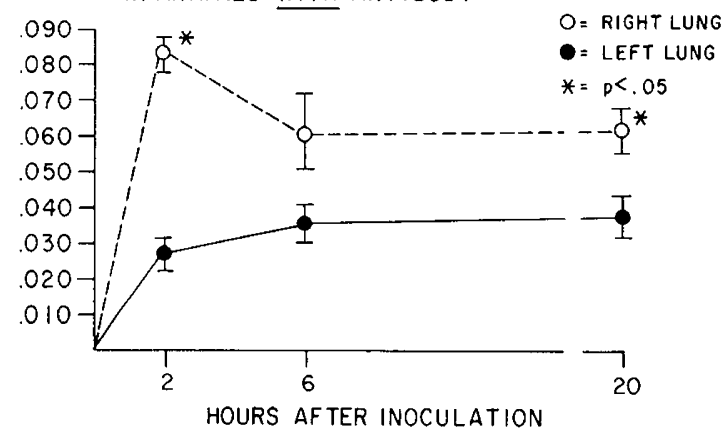

Fig. 4. Upper panel. Lung neutrophil accumulation, quantified by myeloperoxidase assay, in 10 newborn rats inoculated with group B streptococci and no antibody. The open circles signify the right lungs' myeloperoxidase content and the closed circles, the left lungs'. The bracket indicates the standard error of the mean. Lower panel. Lung neutrophil accumulation, quantified by myeloperoxidase assay, in 10 newborn rats inoculated with group B streptococci plus type-specific IgM antibody. The open circles signify the right lungs' myeloperoxidase content and the closed circles, the left lung's. The bracket indicates the standard error of the mean.

animals from developing neutropenia. We inoculated a group of 66 animals with GBS alone, of which $94 \%$ died. In contrast, none of 65 inoculated with GBS $+\mathrm{AB}$ died $(P<0.005)$. When animals were inoculated with GBS plus an antibody that had no affinity for the type III group B streptococcus, no decrease in mortality was observed. This indicates that interaction between the antibody and the bacteria was essential for protection. This observation confirms the previous report, which demonstrated the protective effect of type-specific IgM antibody and establishes the present model as a suitable one for the study of the mechanism of this phenemenon. In order to test the hypothesis that antibody might afford protection by altering or facilitating the neutrophil response, we serially measured the circulating neutrophil concentration, storage neutrophil number, and tissue (lung) neutrophil content in inoculated animals. The group receiving GBS alone exhibited profound neutropenia, a finding previously found to be associated with mortality in human and animal neonates with sepsis $(6,13)$. Such neutropenia, when associated with an extreme left shift, as seen in the present experiments, correlates not only with mortality, but with exhaustion of the neutrophil stores (12). Indeed, when the neutrophil stores were examined, the animals who received GBS alone exhibited marrow exhaustion. In contrast, animals receiving GBS $+\mathrm{AB}$ did not develop neutropenia, and never liberated more than $60 \%$ of their neutrophil reserves. From these observations, we conclude that the administration of type specific antibody prevented the development of neutrophil storage pool exhaustion while preventing mortality. In addition, an earlier release of neutrophils from the neutrophil storage pool occurred in the presence of antibody. Two hours after the inoculation, the antibody recipients had already released about $50 \%$ of their neutrophils reserves but non-antibody animals' reserves had not yet begun to diminish; as if the marrow did not yet recognize the presence of the large bacterial inoculum. Such a delay in mobilization of stored neutrophils might allow early bacterial proliferation and dissemination to occur. Next, we observed that released neutrophils arrived at the area of need, the right lung, in greater numbers and much more quickly when antibody was provided. This rapid release and subsequent prompt tissue accumulation of neutrophils is likely of great value in local containment and rapid elimination of the invading bacteria. The accumulation of neutrophils in the right lung of animals receiving GBS alone was never greater than that of the noninoculated, left lung. This indicates that specific migration of neutrophils toward the injected bacteria was poor in the absence of antibody. The accumulation of neutrophils in the non-injected lung may be explained however, by bilaterial pulmonary infection from intrapulmonary or hematogenous spread of organisms. Alternatively, as has been suggested by Weissmann (34) and Lash et al. (18), perhaps the accumulation of neutrophils in the contralateral lung occurred secondary to chemotactic activation with secondary pulmonary capillary trapping of the cells. Additional studies using both killed and living organisms in neonatal and adult animals with pulmonary and extrapulmonary bacterial inoculation should provide further insight into these questions. In addition, the role of complement in this system requires elucidation.

In conclusion, the present studies confirm the protective effect of type-specific hybridoma antibody in experimental neonatal infection. In addition to acting as an opsonin, the antibody induced an earlier neutrophil response than that occurring with GBS alone. This is evidenced by an earlier release of neutrophils from the storage pool and also by a more rapid accumulation of neutrophils at the site of the bacterial inoculation. Type-specific antibody also acted to limit mobilization of storage neutrophils, whereas animals inoculated with GBS alone developed complete emptying of their neutrophil reserves with profound neutropenia and a maximal left shift. The ability of hybridoma IgM typespecific antibody to facilitate the neutrophil response in vivo and to limit neutrophil storage pool utilization may be significant in the mechanism by which animals are protected from mortality.

\section{REFERENCES AND NOTES}

1. Armstrong, D., Zeligs, B., and Bellanti, J. A.: The inflammatory response of the neonatal rat to streptococcal infection. Pediatr. Res., 14: 445 (A) (1980).

2. Baker, C. J. and Kasper, D. L.: Correlation of maternal antibody deficiency with susceptibility to neonatal group B streptococcal infection. N. Engl. J. Med., 294: 753 (1976).

3. Bradley, P. P., Priebat, D. A., Christensen, R. D., and Rothstein G.: Measurement of cutaneous inflammation: estimation of neutrophil content with an enzyme marker. J. Invest. Derm., 78: 208 (1982).

4. Bradley, P. P., Christensen, R. D., and Rothstein, G.: Cellular and extracellular myeloperoxidase in pyogenic inflammation. Blood, 60: 618 (1982).

5. Christensen, R. D., Shigeoka, A. O., Hill, H. R., and Rothstein, G.: Circulating and storage neutrophil changes in experimental type II group b streptococcal sepsis. Pediatr. Res., 14: 806 (1980).

6. Christensen, R. D., Macfarlane, J. L., Taylor, N. L., Hill, H. R., and Rothstein, G.: Blood and marrow neutrophils during experimental group B streptococcal infection: quantification of the stem cell, proliferative, storage and circulating pools. Pediatr. Res., 16: 549 (1982).

7. Christensen, R. D., Bradley, P. P., Priebat, D. A., Anstall, H. B., and Rothstein, G.: Granulocyte transfusion in septic canine neonates. Pediatr. Res., 16: 57 (1982).

8. Christensen, R. D. and Rothstein G.: Efficiency of neutrophil migration in the neonate. Pediatr. Res., 14: 1147 (1980).

9. Christensen, R. D., Anstall, H. B., and Rothstein G.: Use of whole blood exchange transfusion to supply neutrophils to septic, neutropenic neonates. Transfusion, 22: 504 (1982).

10. Christensen, R. D., Rothstein, G., Anstall, H. B., and Bybee, B.: Granulocyte transfusions in neonates with bacterial infection, neutropenia, and depletion of mature marrow neutrophils. Pediatrics, 70: 1 (1982).

11. Christensen, R. D., Hill, H. R., and Rothstein G.: Granulocytic stem cell (CFUc) proliferation in experimental group B streptococcal sepsis. Pediat. Res., 17: 278 (1983).

12. Christensen, R. D. and Rothstein G.: Exhaustion of mature marrow neutrophils in neonates with sepsis. J. Pediatr., 96: 316 (1980).

13. Christensen, R. D., Bradley, P. P., and Rothstein, G.: The leukocyte left shift in clinical and experimental neonatal sepsis. J. Pediatr., 98: 101 (1981).

14. Erdman, S. H., Christensen, R. D., Bradley, P. P., and Rothstein, G.: The supply and release of marrow neutrophils: A developmental study. Biol. Neo., 41: 132 (1982).

15. Forman, M. L. and Stiehm, E. R.: Impaired opsonic activity but normal phagocytosis in low-birth-weight infants. N. Engl. J. Med. 281: 926 (1969). 
16. Klein, R. B., Fischer, T. J., Gard, S. E., Biberstein, M., and Steim, E. R. Decreased mononuclear and polymorphonuclear chemotaxis in newborns. Pediatrics, 60: 467 (1977).

17. Lancefield, R. C.: A micro-precipitin technique for classifying hemolytic streptococci and improved methods for producing antisera. Proc. Soc. Exp. Biol. Med., 38: 473 (1938)

18. Lash, J. A., Coats, T. D., Baehner, R. L., and Boxer, L. A.: Plasma lactoferrin reflects granulocyte activation in vivo. Pediatr. Res. (abstract), 16: 208A (1982)

19. Laurenti, F., LaGreca, G., Ferro, R., and Bucci, G.: Transfusion of polymorphonuclear neutrophils in a premature infant with Klebsiella sepsis. Lancet, 2: 111 (1978).

20. Laurenti, F., Ferro, R., Isacchi, G., Panero, A., Salvignono, P. G., Malagino, R., Palmero, D. and Bucci, G.: Polymorphonuclear leukocyte transfusion for the treatment of sepsis in the newborn infant. J. Pediatr., 98: 188 (1981).

21. McCracken G. H., Jr. and Eichenwald, H. F.: Leukocyte function and the development of opsonic and complement activity in the neonate. Am. J. Dis. Child., 121: 120 (1971).

22. Miller, M. E.: Host Defences in the Human Neonate. pp 1-3. Grune and Stratton Inc., New York, N.Y. (1978).

23. Miller, M. E.: Chemotactic function in the human neonate: Humoral and cellular aspects. Pediatr. Res., 5: 487 (1971).

24. Miller, M. E.: Pathology of chemotaxis and random mobility. Semin. Hematol., 12: 59 (1975).

25. Pincus, S. H., Ewing, L. P. and Stocks, C. J.: Anti -(T,G)-A--L Hybrdomas. Fine specificity and idiotypic characterization. Molecular Immunol., 19: 1551 (1982)

26. Rote, N. S., Taylor, N. L., Shigeoka, A. O., Scott, J. R., and Hill, H. R.: Enzymelinked immunosorbent assay for group B streptococcal antibodies. Infect. Immun., 27: 118 (1980).

27. Santos, J. I., Shigeoka, A. O., and Hill H. R.: Functional leukocyte administration in protection against experimental neonatal infection. Pediar. Res., 14: 1400 (1980).

28. Santos, J. I., Shigeoka, A. O., Rote, N. S., and Hill, H. R.: Protective efficacy of a modified immune serum globulin in experimental group B streptococcal infection. J. Pediatr., 99: 873 (1981)

29. Shigeoka, A. O., Pincus, S. H., Rote, N. S., and Hill H. R.: Hybridoma typespecific IgM antibody offers enhanced protection against systemic or respiratory group B streptococcal experimental infection. Pediatr. Res. (abstract), 16: 231A (1982).

30. Shigeoka, A. O., Hall, R. T., and Hill H. R.: Blood transfusion in group B streptococcal sepsis. Lancet, 1: 636 (1978).

31. Tollner, U., Pohlandt, F., Heinze, F., and Henrichs, I.: Treatment of septicemia in the newborn infant: choice of initial antimicrobial drugs and the role of exchange transfusion. Acta Paedictr. Scand., 66: 605 (1977).

32. Vain, N. E., Mazulmain, J. R., Swarner, O. W., and Cha, C. C.: Role of exchange transfusion in the treatment of severe septicemia. Pediatrics, 66: 693 (1980).

33. Wasserman, R. L.: Neonatal sepsis: the potential of granulocyte transfusion. Hosp. Pract., 17: 95 (1982).

34. Weissmann, G., Smolen, J. E., and Korchak, H. M.: Release of inflammatory mediators from stimulated neutrophils. N. Engl. J. Med., 303: 27 (1980).

35. The authors thank Nancy Taylor, Jayne Blair, Peter Viavant for technical assistance.

36. Requests for reprints should be addressed to: Robert D. Christensen, M.D Division of Hematology, University of Utah School of Medicine, 50 North Medical Drive, Salt Lake City, Utah, 84132.

37. Supported by two grants from the Thrasher Research Fund and by U.S. Public Health Service Grants \#HD-14419, AI-13150 and AI-19094

38. Received for publication October 6, 1982.

39. Accepted for publication February 18, 1983

\title{
Lymphocyte-Derived Chemotactic Factor Production by Neonatal Lymphocytes
}

\author{
MARGARET A. KELLER, ${ }^{(18)}$ ROSE M. KIDD, ROSEMARY D. LEAKE, AND SUSAN L. EVERETT \\ Department of Pediatrics, UCLA School of Medicine, Harbor-UCLA Medical Center, Torrance, California USA
}

\section{Summary}

We examined neonatal lymphocyte production of the lymphokine, Iymphocyte-derived chemotactic factor (LDCF). Supernatants from 10 neonatal lymphocyte cultures were paired with the supernatants from 10 adult lymphocyte cultures. Chemotactic activity was defined as the number of adult monocytes migrating toward phytohemagglutinin-stimulated supernatants minus the number of monocytes migrating toward nonstimulated control supernatants using a blind well chamber assay. Eight of the 10 neonatal lymphocyte cultures produced LDCF and five of the 10 adult lymphocyte cultures showed LDCF activity. The mean number of monocytes migrating toward neonatal supernatants was $13.0 \pm 1.5$ and toward adult supernatants was $14.1 \pm 2.1$. To determine if a quantitative difference in LDCF production did exist, six additional experiments were performed assaying multiple dilutions of supernatants. No evidence was found for a quantitative difference in neonatal LDCF production compared to adult production. Our studies show that neonatal mononuclear cells are functionally as competent as adult mononuclear cells to produce LDCF in response to a mitogen challenge.

\section{Abbreviations}

HBSS, Hanks' balance salt solution LDCF, lymphocyte-derived chemotactic factor
MIF, migration inhibition factor

PHA, phytohemagglutinin

PPD, tuberculin, purified protein derivative

The newborn infant's increased susceptibility to viral, fungal, and protozoal infections is consistent with impaired cellular immunity. Although absolute numbers of $\mathrm{T}$ cells and mitogen-induced $\mathrm{T}$ cell proliferation has been normal in peripheral blood obtained from neonates $(16,17)$, a number of investigators have documented impaired cutaneous hypersensitivity (16). Fireman et al. (8) have shown that neonates are deficient in their ability to show skin test reactivity to PPD antigen. The neonates studied were given transfer factor or leukocytes from PPD positive mothers. Their peripheral lymphocytes were then capable of responding to PPD by blastogenesis and capable of passively transfering skin test reactivity to adults yet these neonates could not develop a positive skin test themselves. These abnormal skin test responses may indicate a functional defect of neonatal lymphocytes or macrophages in producing important mediators of inflammation or may indicate impaired responses of neonatal monocytes and polymorphonuclear cells to inflammatory mediators.

Lymphokines, immunologic mediators produced by lymphocytes, have been shown to be an important component in delayed hypersensitivity (1), but it is still not clearly defined which lymphokine is responsible for the typical accumulation of mononu- 